\title{
TEM and SIMS Analysis of (100), (110), and (111) Single Crystal Niobium
}

\author{
A. D. Batchelor ${ }^{1}$, D. N. Leonard ${ }^{2}$, P. E. Russel1 ${ }^{3}$, F. A. Stevie ${ }^{1}$, \\ D. P. Griffis ${ }^{1,2}$, G. R. Myneni ${ }^{4}$ \\ ${ }^{1}$ Analytical Instrumentation Facility, North Carolina State University, MRC Building. Room 318, \\ Raleigh, NC, 27695-7531 \\ ${ }^{2}$ Materials Science Department, North Carolina State University, EB1 Building, Raleigh, NC 27695 \\ ${ }^{3}$ Appalachian State University, 231 CAP Building, 525 Rivers St., Boone, NC 28608 \\ ${ }^{4}$ Jefferson Lab, 12000 Jefferson Ave., Newport News, VA 23606
}

\begin{abstract}
Single crystal niobium specimens of (100), (110) and (111) crystal orientations have been analyzed using TEM and SIMS. The TEM specimens were prepared using Focused Ion Beam (FIB) and show niobium oxide thicknesses ranging from 4.9 to $8.3 \mathrm{~nm}$ for the three specimens after buffer chemical polishing. The oxide layers appear uniform and no significant sub-oxide region was noted. SIMS analysis was made for all three orientations on hydrogen, carbon, and oxygen before and after heat treatments at 90,600 , and $1250^{\circ} \mathrm{C}$. Hydrogen is at a high level between the oxide layer and niobium, but at a relatively low level in the oxide. No high oxygen concentration region was noted in the niobium below the oxide. $\mathrm{C}$ contamination on the surface is detected mainly at the surface. Analysis after heat treatments showed some decrease in hydrogen after the $600^{\circ} \mathrm{C}$ heat treatment, and significant oxidation of the niobium after the $1250^{\circ} \mathrm{C}$ heat treatment.
\end{abstract}

Keywords: Superconducting materials, accelerators, TEM, SIMS

PACS: 74.70.-b, 74.72.-h, 68.37.Lp, 68.49.Sf, 82.80.Ms, 29.17.+w

\section{INTRODUCTION}

Niobium is the material of choice for superconducting accelerator structures because of its high critical temperature $(\mathrm{Tc}=9.2 \mathrm{~K})$, critical magnetic field $(\sim 200 \mathrm{mT})$ among the pure metals, and easy formability. It is important to understand the properties of the surface and near surface region of the niobium because the penetration range of electromagnetic fields into the superconductor is on the order of $60 \mathrm{~nm}$. The model of the $\mathrm{Nb}$ surface consists of a layer of hydrocarbon contamination on $\mathrm{Nb}_{2} \mathrm{O}_{5}$ on suboxide layers, with deeper oxygen at cracks in the $\mathrm{Nb}$ [1]. Surface treatments of the $\mathrm{Nb}$ have produced improved superconductor radio frequency (SRF) accelerator cavity performance. XPS analysis after $1950^{\circ} \mathrm{C}$ heat treatment appeared to show $\mathrm{Nb}$ covered with $\mathrm{NbO}$, followed by $\mathrm{NbO}_{2}$ and $\mathrm{Nb}_{2} \mathrm{O}_{5}$ [2]. XPS and AES analysis of $\mathrm{Nb}$ after $1850^{\circ} \mathrm{C}$ heat treatment in vacuum followed by chemical and electropolishing appeared to show an $\mathrm{NbO}-\mathrm{NbO}_{2}$ layer $\sim 1 \mathrm{~nm}$ thick on $\mathrm{Nb}$ covered with $2 \mathrm{~nm}$ $\mathrm{Nb}_{2} \mathrm{O}_{5}$ immediately after oxidation, and with slow growth the total oxide layer reaches $6 \mathrm{~nm}$ [3]. The oxidation behavior of $\mathrm{Nb}$ with different heat treatments/bakes is not yet 
completely understood and continues to be an object of study, especially with enhanced analytical methods, such as angle resolved XPS [4].

Characterization of the top $60 \mathrm{~nm}$ of the niobium requires techniques with good depth resolution. However, the surface roughness of the $\mathrm{Nb}$ complicates analysis for almost any analytical technique. Transmission Electron Microscopy (TEM) can provide atomic scale spatial resolution with cross sectional images of the near surface region. No TEM analysis of SRF $\mathrm{Nb}$ has been noted before this study. Secondary Ion Mass Spectrometry (SIMS) has good depth resolution and is one of the few techniques that can analyze hydrogen. SIMS analysis of superconducting niobium has been limited [5] and is essentially nonexistent for analysis of single crystal niobium. SIMS analysis of a metal is affected by non-uniform sputtering and a rough surface will negatively affect the depth resolution. [6]

Niobium is a soft metal and therefore traditional polishing methods used to prepare samples for TEM analysis will smear the surface and can embed polishing material. Focused ion beam (FIB) sample preparation using a gallium ion beam has been shown to provide high quality TEM samples for a wide array of materials, including metals. [8,9] The niobium samples for this TEM investigation were prepared using the FIB direct lift-out technique which only entails consumption of a small volume of sample $(\sim 20 \mu \mathrm{m} \times 30 \mu \mathrm{m})$ allowing many samples to be prepared from a single sample if required.

The intentions of this study are to measure the single crystal niobium oxide thickness with cross sectional TEM images for different crystal orientations and to monitor the near surface region for hydrogen, oxygen, and carbon using SIMS.

\section{EXPERIMENTAL METHOD}

Single crystal polished niobium specimens (10mm in diameter and $2 \mathrm{~mm}$ thick) of (100), (110), and (111) orientation were obtained from MaTeck [7]. Each sample was cut into four pieces. The cut pieces were treated by standard buffered chemical polishing prior to analysis and heat treatments. The heat treatments were $90^{\circ} \mathrm{C} 20 \mathrm{hr}$ in vacuum, $600^{\circ} \mathrm{C} 10 \mathrm{hr}$ in vacuum, and $1250^{\circ} \mathrm{C} 3 \mathrm{hr}$ in vacuum and enclosed in a titanium box.

Roughness of the niobium surface is a major concern. Roughness was significant on the samples as received and roughness varied over the sample set. Roughness on the (100) sample was measured with a profilometer as $0.6 \mu \mathrm{m}$ peak to peak and $0.13 \mu \mathrm{m}$ RMS. The sample surface of the (100) after $600^{\circ} \mathrm{C}$ heat treatment showed $1.0 \mu \mathrm{m}$ peak to peak and $0.1 \mu \mathrm{m}$ RMS.

All sample preparation using focused ion beam (FIB) micromachining was performed with a Hitachi FB-2100 focused ion beam instrument. Since the surface is of primary interest, special precautions were taken to protect the surface during FIB sample preparation for TEM. TEM samples were prepared by first coating the surface with $60 \mathrm{~nm}$ of gold-palladium. The localized regions where samples were to be removed for TEM analysis were additionally coated with $2 \mu \mathrm{m}$ of FIB deposited tungsten. The samples were then cut free of the bulk of the sample and attached to TEM grids using the tungsten deposition capability and the in-situ lift-out arrangement on this instrument. All further thinning of the samples was conducted on the TEM 
grids. Because of the high density of the materials, the samples had to be thinned beyond what would be necessary for less dense materials in order to obtain good quality micrographs. This required an iterative process where the samples were thinned on the FIB, put into the TEM to check the image quality, and then returned as needed to the FIB for further thinning. TEM bright field micrographs were obtained using a JEOL JEM2010F high resolution TEM/STEM equipped with a Gatan 794 Multiscan CCD camera and a Gatan GIF 200 image intensifier for recording of TEM micrographs.

Samples before and after the 90,600 , and $1250^{\circ} \mathrm{C}$ heat treatments were analyzed using a CAMECA IMS-6F magnetic sector SIMS instrument with cesium primary beam. Impact energy for $\mathrm{Cs}^{+}$was $6 \mathrm{keV}$ with incidence angle of $24^{\circ}$ from normal. A beam current of $3 \mathrm{nA}$ was rastered over a $160 \mu \mathrm{m} \times 160 \mu \mathrm{m}$ area and ions detected from a $30 \mu \mathrm{m}$ diameter region at the center of the crater. Analyses were made at a mass resolution $(\mathrm{M} / \Delta \mathrm{M})$ of 500 . The analysis of residual gas elements such as hydrogen, carbon, and oxygen should be made under high vacuum conditions. Samples were pumped to $\sim 1 \times 10^{-9}$ Torr in an entry chamber before insertion into the specimen chamber and analyses were made with analysis chamber pressure of approximately $2 \times 10^{-10}$ Torr. Measurements were taken on at least two sites for each sample. SIMS depth resolution of metals is typically affected by differential sputtering resulting from the differing sputtering rates of the various crystal grain orientations with respect to the ion beam. The result of this differential sputtering is a non-uniform surface and a degraded depth resolution. In the case of a single crystal specimen, this effect should be reduced. However, the single crystal sample surfaces were still quite rough for a SIMS measurement and have many surface irregularities. While it is not possible to quantify the effect, these surface irregularities significantly reduce depth resolution.

Sputtering rate was determined by sputtering a region for an extended period of time so that the crater depth was sufficient to be measured despite the surface roughness. The sputtering rate obtained is $0.05 \mathrm{~nm} / \mathrm{sec}$ or $50 \mathrm{~nm}$ at $100 \mathrm{sec}$ for the depth profiles shown.

\section{TEM RESULTS}

Cross section TEM analysis was obtained on samples that had not been heat treated for the three crystal orientations. The results are shown in Fig. 1-3 and tabulated in Table 1. The oxide thicknesses vary between 4.9 and $8.3 \mathrm{~nm}$.

Prior to the TEM analysis of the Nb samples, the TEM magnifications used for this analysis were calibrated using a $\mathrm{Si}(100)$ crystal standard. In order to improve the measurement accuracy of the respective $\mathrm{Nb}$ oxides, Gatan Digital Micrograph software was used to select a region of the micrographs containing the oxides (see "boxes" on Figures 1-3). The boxed regions were selected to allow measurement of a thousand lines over the length of the box. These lines, which are perpendicular to the oxide thickness, were then averaged to obtain the oxide thickness for each sample. 
Table 1: TEM Results

\begin{tabular}{|c|c|}
\hline Sample & Oxide thickness $(\mathbf{n m} \pm \mathbf{0 . 5})$ \\
\hline $\mathbf{( 1 0 0 )}$ & 4.9 \\
\hline $\mathbf{( 1 1 0 )}$ & 8.3 \\
\hline $\mathbf{( 1 1 1 )}$ & 7.5 \\
\hline
\end{tabular}

\section{SIMS RESULTS}

SIMS analyses were performed on samples before and after the three heat treatments for all three crystal orientations. All crystal orientations produced similar results. Fig 4-7 show SIMS depth profiles of secondary ion intensity versus time for (100) niobium before and after the heat treatments. Hydrogen, carbon, and oxygen were detected and an oxide layer was evident on all samples. The roughness of the sample surfaces prevented measurement of the crater depths for the analyses shown, but from the measurement discussed in the experimental section, the profiles are at approximately $300 \mathrm{~nm}$ after $600 \mathrm{sec}$ sputtering. Since there are no standards in $\mathrm{Nb}$ for the elements of interest, elemental concentrations can only be estimated. A comparison of the $\mathrm{H}$ levels obtained with that obtained from an $\mathrm{H}$ implant in $\mathrm{Si}$ indicates the $\mathrm{H}$ is at a high (estimated to be $>1 \%$ ) level in the $\mathrm{Nb}$. The hydrogen after $600^{\circ} \mathrm{C}$ heat treatment was less than that of the not heat treated and $90^{\circ} \mathrm{C}$ heat treated samples. Figure 8 shows the ratio of $\mathrm{H}$ to $\mathrm{Nb}$ for the (100) samples. There was no evidence of a high oxygen content region below the oxide except for the $1250^{\circ} \mathrm{C}$ sample. All of the $1250^{\circ} \mathrm{C}$ heat treated samples were heavily oxidized over the depth measured using SIMS. Figure 9 shows the $\mathrm{O}$ to $\mathrm{Nb}$ ratio for the (100) samples. For all samples, carbon is at a high concentration at the surfaces and then decreases rapidly. Some of the samples after heat treatment showed very interesting surface topography. Fig. 10 is an optical micrograph of the surface of the (100) sample after $600^{\circ} \mathrm{C}$ heat treatment and indicates the $30 \mu \mathrm{m}$ diameter SIMS analysis region is comparable to the size of the circular shaped features on the sample surface.

SIMS analysis for Ti contamination from the $1250^{\circ} \mathrm{C}$ heat treatment in Ti box was made on the (100) and (111) samples using $\mathrm{O}_{2}^{+}$primary beam on the CAMECA IMS$6 \mathrm{~F}$. Both samples showed very high Ti concentration through the oxide. Comparison of Ti secondary ion intensity obtained from these samples with that obtained from a $\mathrm{Ti}$ implanted silicon standard indicated that the Ti concentration almost certainly exceeds $1 \%$ atomic and this was confirmed with EDS measurements at 10 and $20 \mathrm{kV}$ that showed $\mathrm{Ti}$ as a major constituent. A decrease of the Ti intensity was observed when the electron energy was increased from 10 to $20 \mathrm{kV}$. This clearly indicates that the Ti is concentrated near the surface of the $\mathrm{Nb}$. The EDS measurements were made on a Hitachi 3200 variable pressure SEM with Oxford EDS system.

Mass spectra acquired from various $\mathrm{Nb}$ samples indicated the presence of intense peaks at masses indicative of $\mathrm{NbH}^{-}, \mathrm{NbH}_{2}^{-}, \mathrm{NbH}_{3}^{-}, \mathrm{NbH}_{4}^{-}$, and a weaker $\mathrm{NbH}_{5}^{-}$. These secondary ion species are unexpected and support the conclusion of a high concentration of $\mathrm{H}$ present in these samples. An early study of hydrogen in hydrogen 
embrittled $\mathrm{Nb}$ [10] was made using an $\mathrm{O}_{2}{ }^{+}$primary beam with detection of positive secondary ions, but only $\mathrm{Nb}^{+}$and $\mathrm{NbH}^{+}$were noted. Mass spectra obtained using $\mathrm{O}_{2}^{+}$ on our instrument confirmed the presence of $\mathrm{NbH}^{+}$and lack of significant $\mathrm{NbH}_{\mathrm{x}}^{+}$ where $\mathrm{x}$ is 2 or higher. Further work is needed to understand the observed ion species, and the importance of the $\mathrm{NbH}_{\mathrm{x}}{ }^{-}$ions.

\section{SUMMARY AND CONCLUSIONS}

The TEM micrographs clearly show the thickness and uniformity of the niobium oxide for these single crystal samples. No significant suboxide region was observed. It is not certain whether the variations in oxide thickness for the different orientations are significant because only one specimen was prepared from each orientation.

The SIMS results show low hydrogen content in the oxide but show high concentrations of hydrogen in the near surface niobium below the oxide. The oxide on the surface of the sample heat treated at $1250^{\circ} \mathrm{C}$ extended beyond the depth probed by SIMS and this oxide showed high $\mathrm{H}$ concentration throughout. No significant differences were noted between the different crystal orientations.

While these results are clearly preliminary, they are significant since there is no other TEM data and very limited SIMS data available in the literature. More measurements are needed on single crystal niobium, and comparative measurements on polycrystalline niobium, to gain a better understanding of the surface oxidation and to determine how the heat treatment affects the physical and chemical properties of the niobium. The results of this study may contradict earlier studies on polysilicon niobium, but these results have better depth resolution and these results are on single crystal niobium.

\section{ACKNOWLEDGMENTS}

This work is supported in part by DOE contract DE-AC05-84ER40150 The authors acknowledge discussions with Drs. P. Kneisel and G. Ciovati and their help in getting the samples prepared. We acknowledge the assistance of Danny Forehands in the heat treating of the samples and R. Garcia for EDS measurements. 


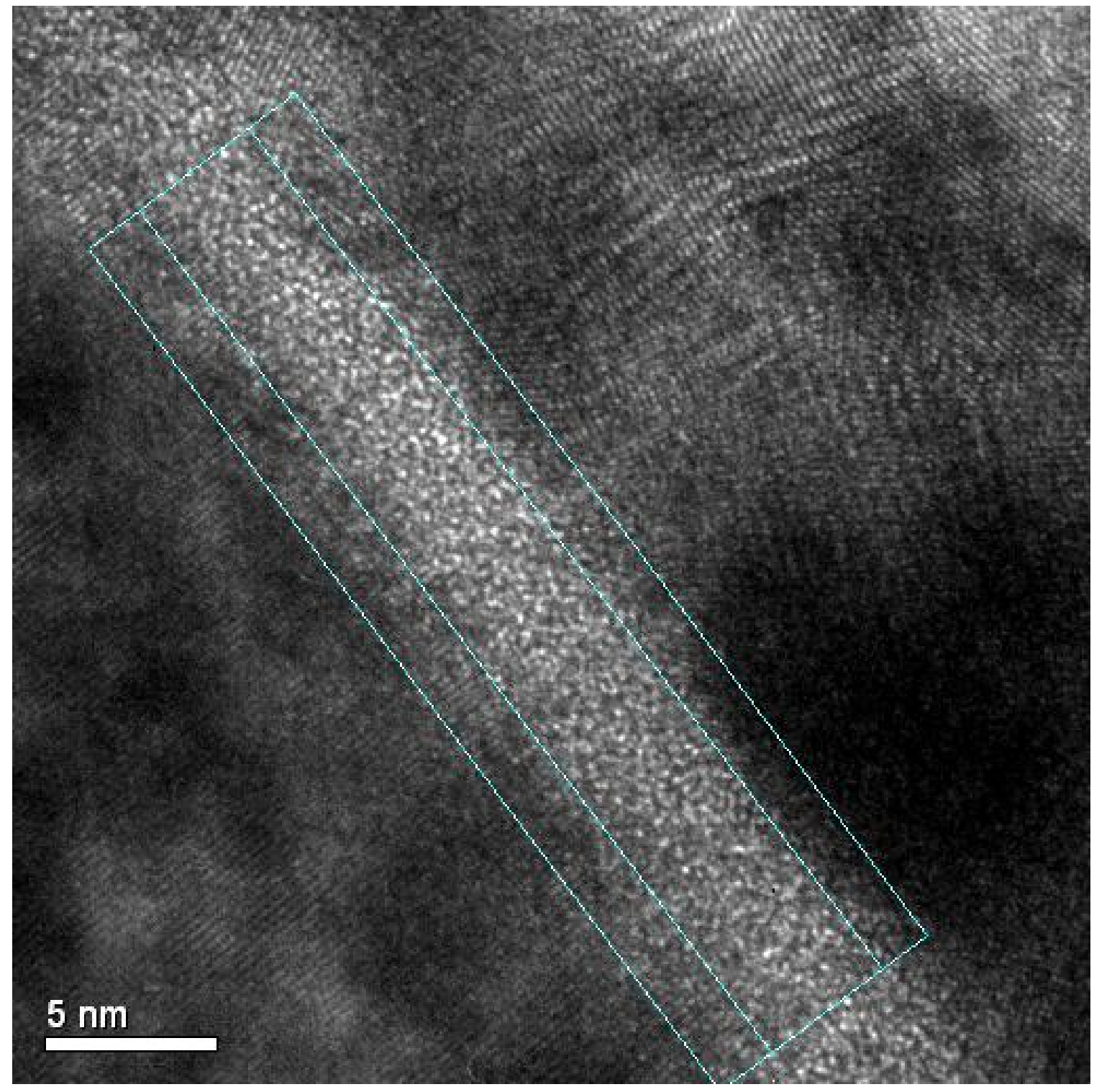

FIGURE 1. Cross section TEM micrograph of (100) as received sample showing niobium oxide thickness. 


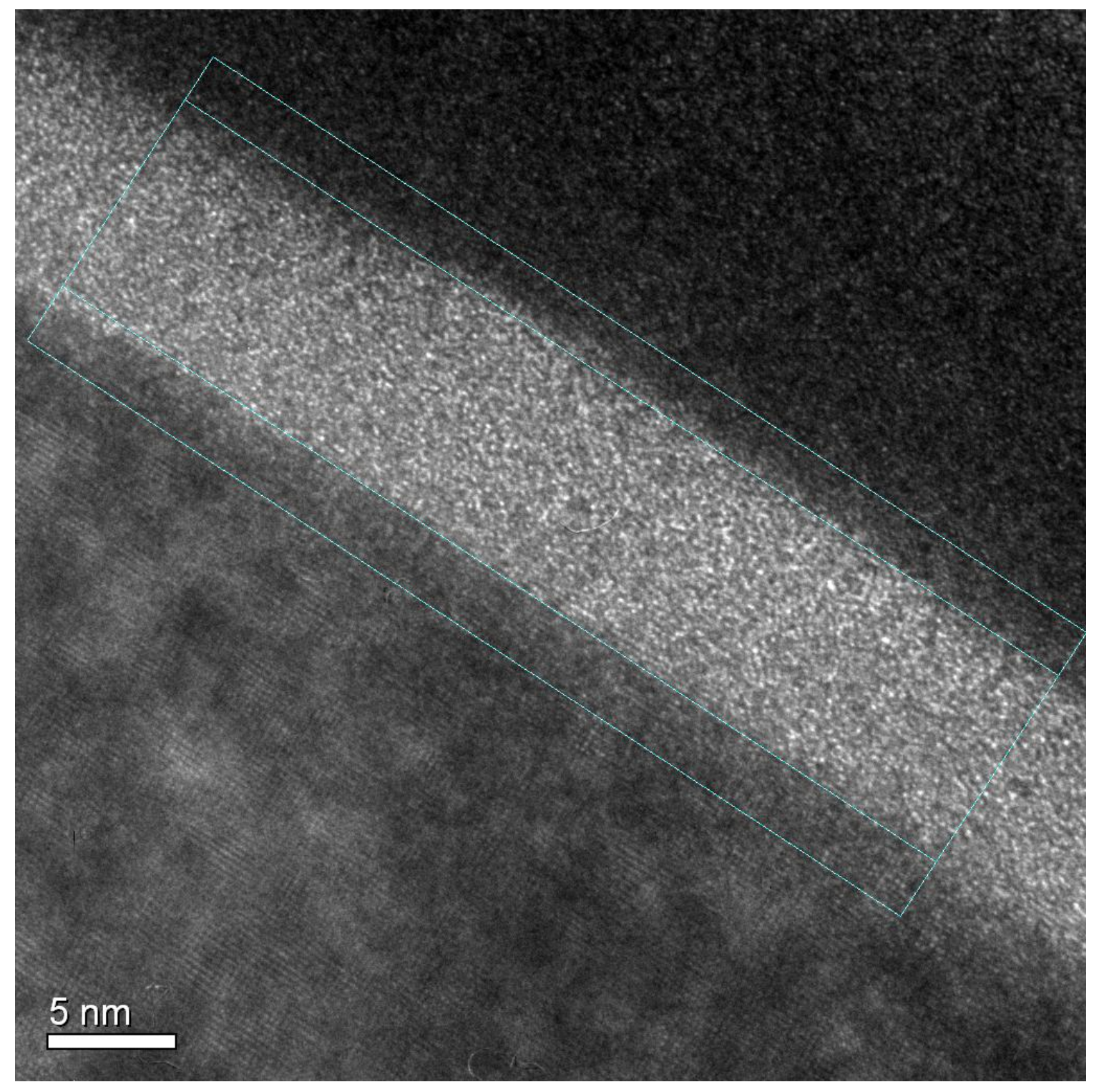

FIGURE 2. Cross section TEM micrograph of (110) as received sample showing niobium oxide thickness. 


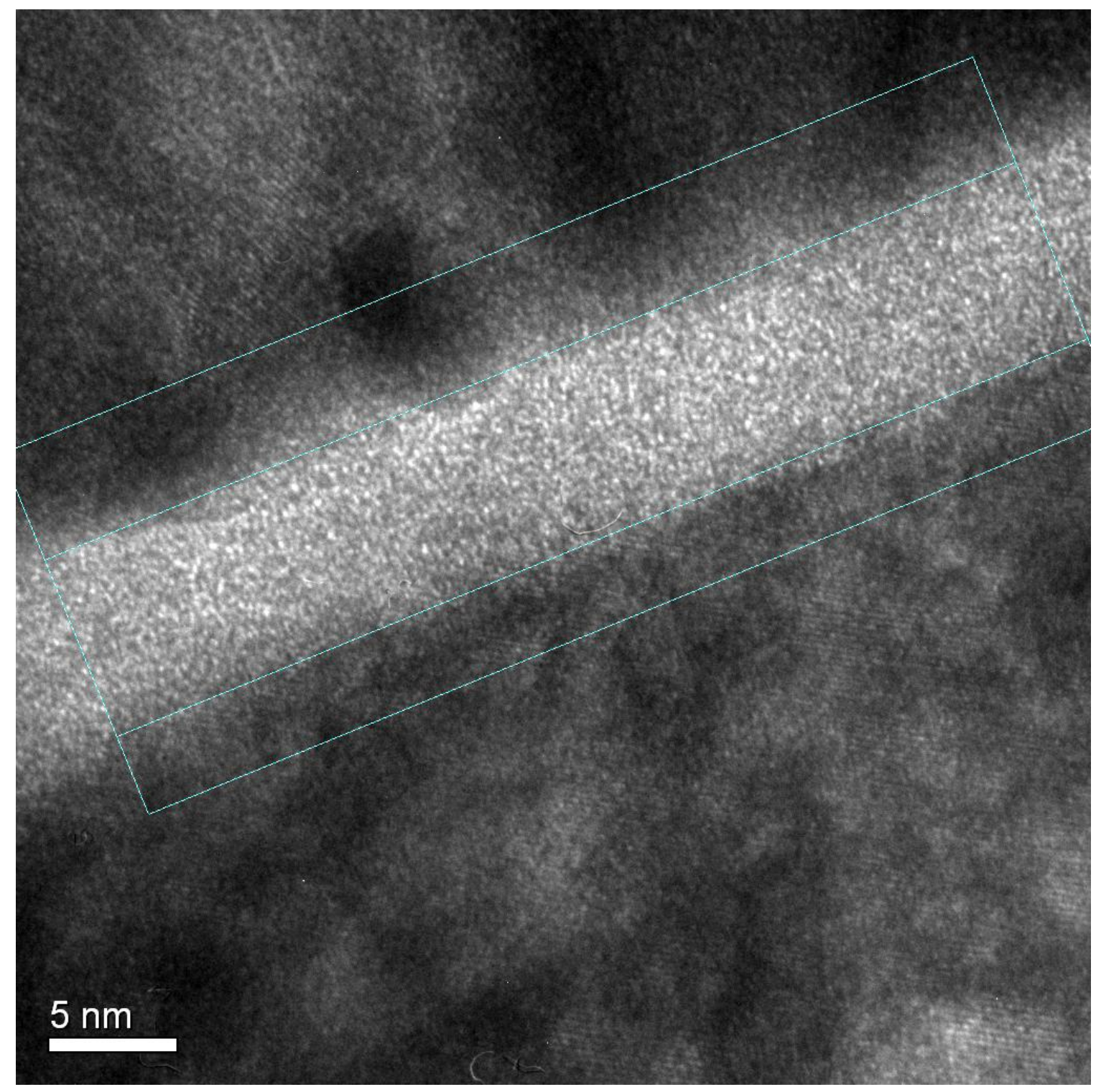

FIGURE 3. Cross section TEM micrograph of (111) as received sample showing niobium oxide thickness. 


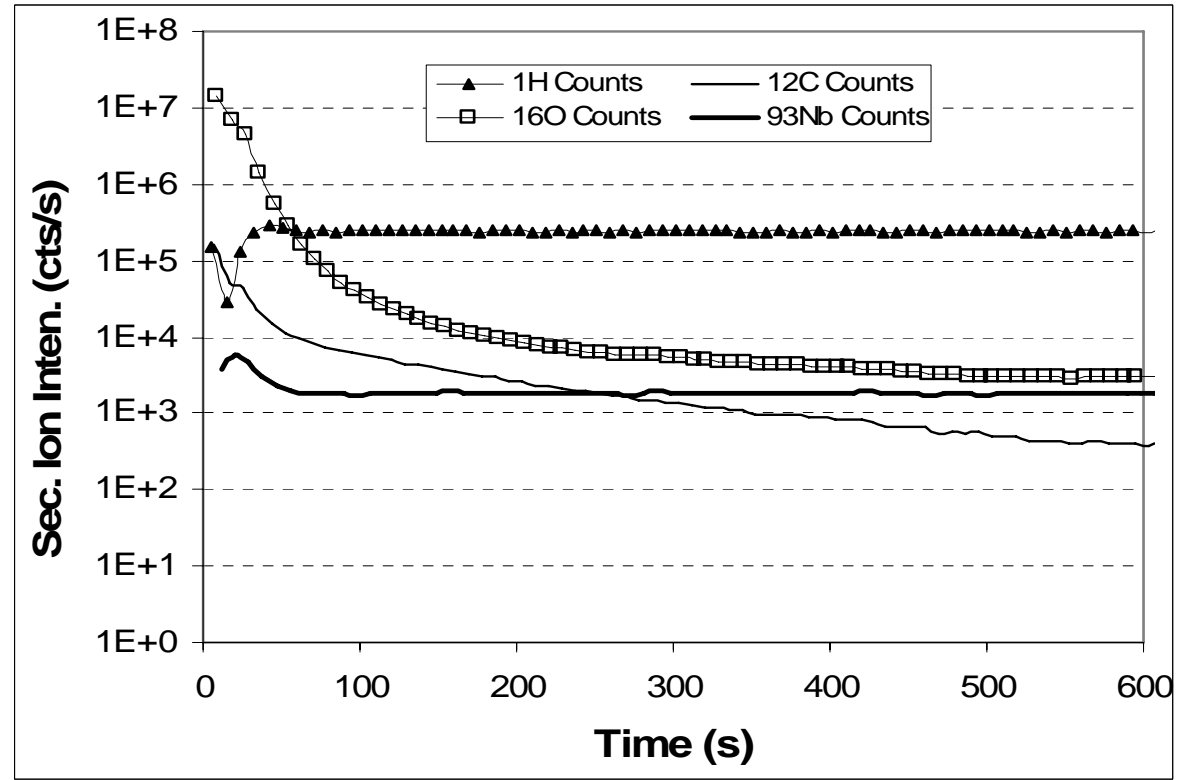

FIGURE 4. SIMS depth profile of (100) sample not heat treated

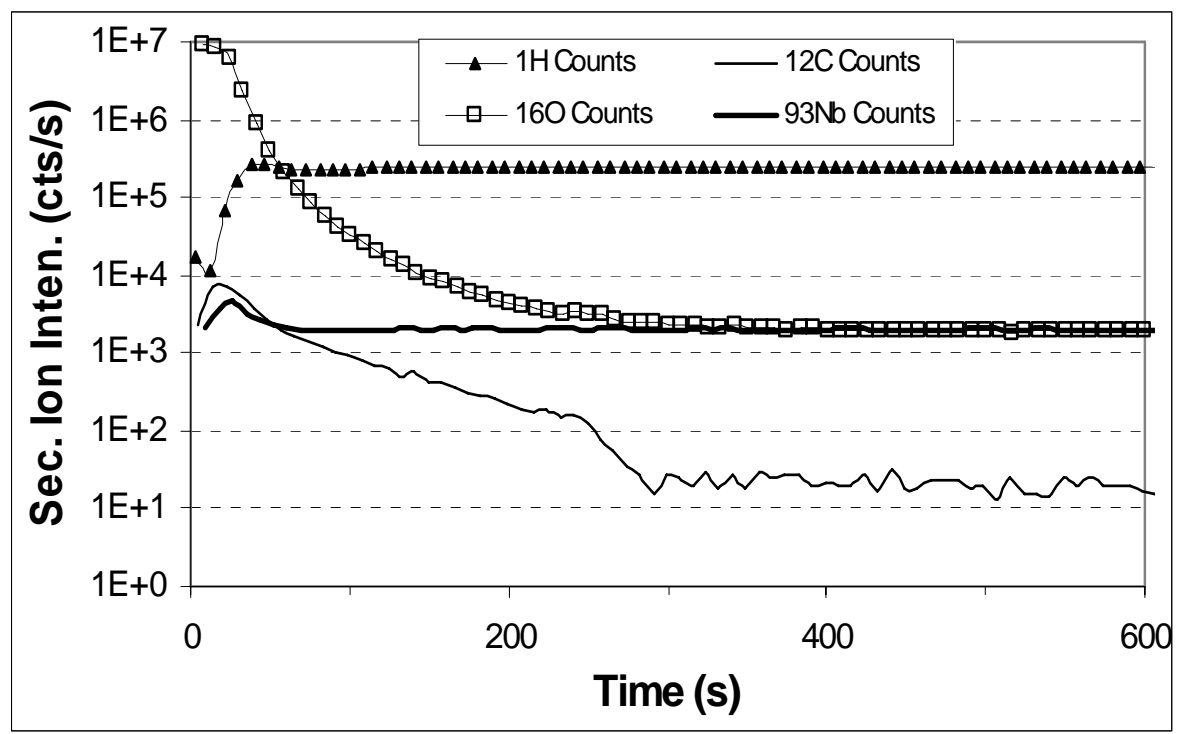

FIGURE 5. SIMS depth profile of (100) sample after $90^{\circ} \mathrm{C}$ heat treatment 


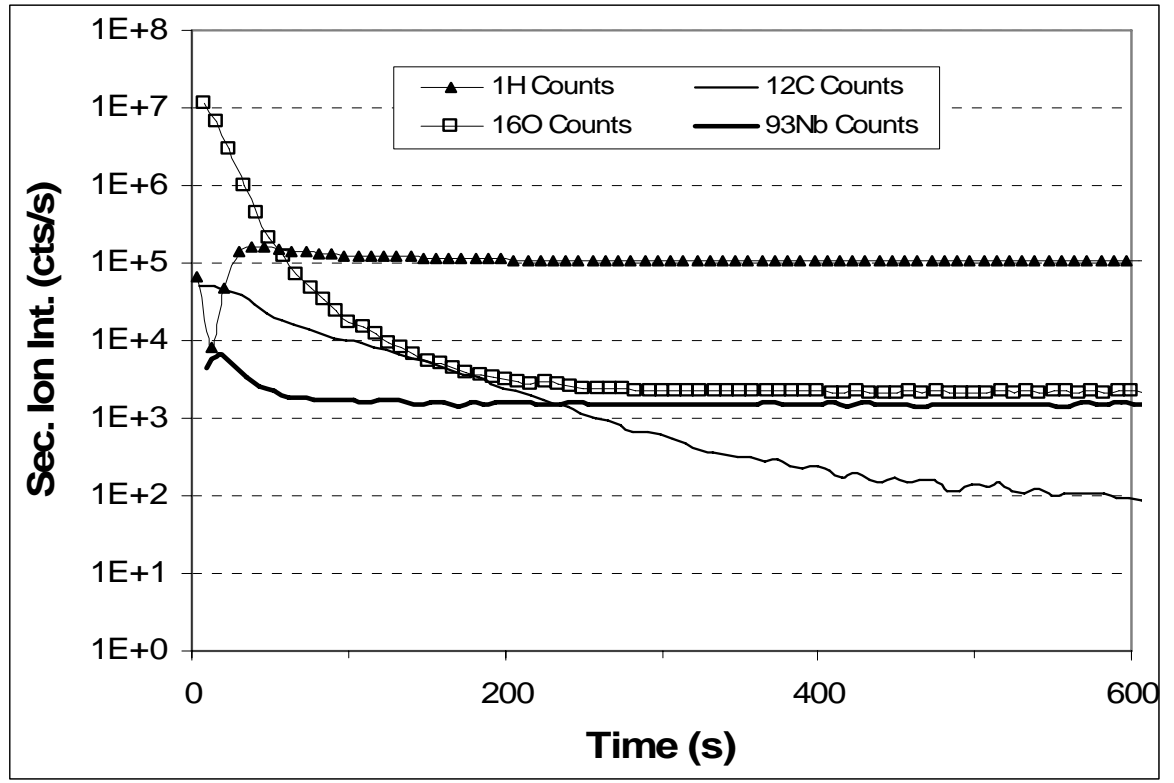

FIGURE 6. SIMS depth profile of $(100)$ sample after $600^{\circ} \mathrm{C}$ heat treatment

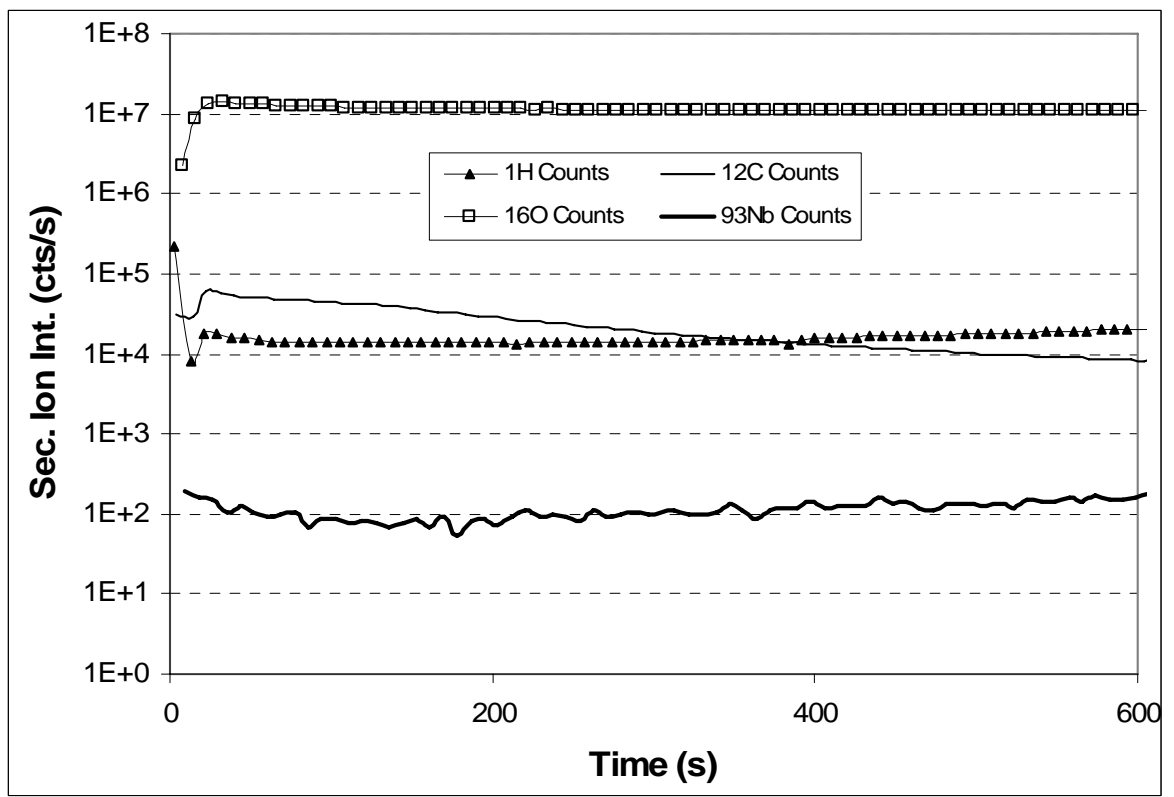

FIGURE 7. SIMS depth profile of (100) sample after $1250^{\circ} \mathrm{C}$ heat treatment 


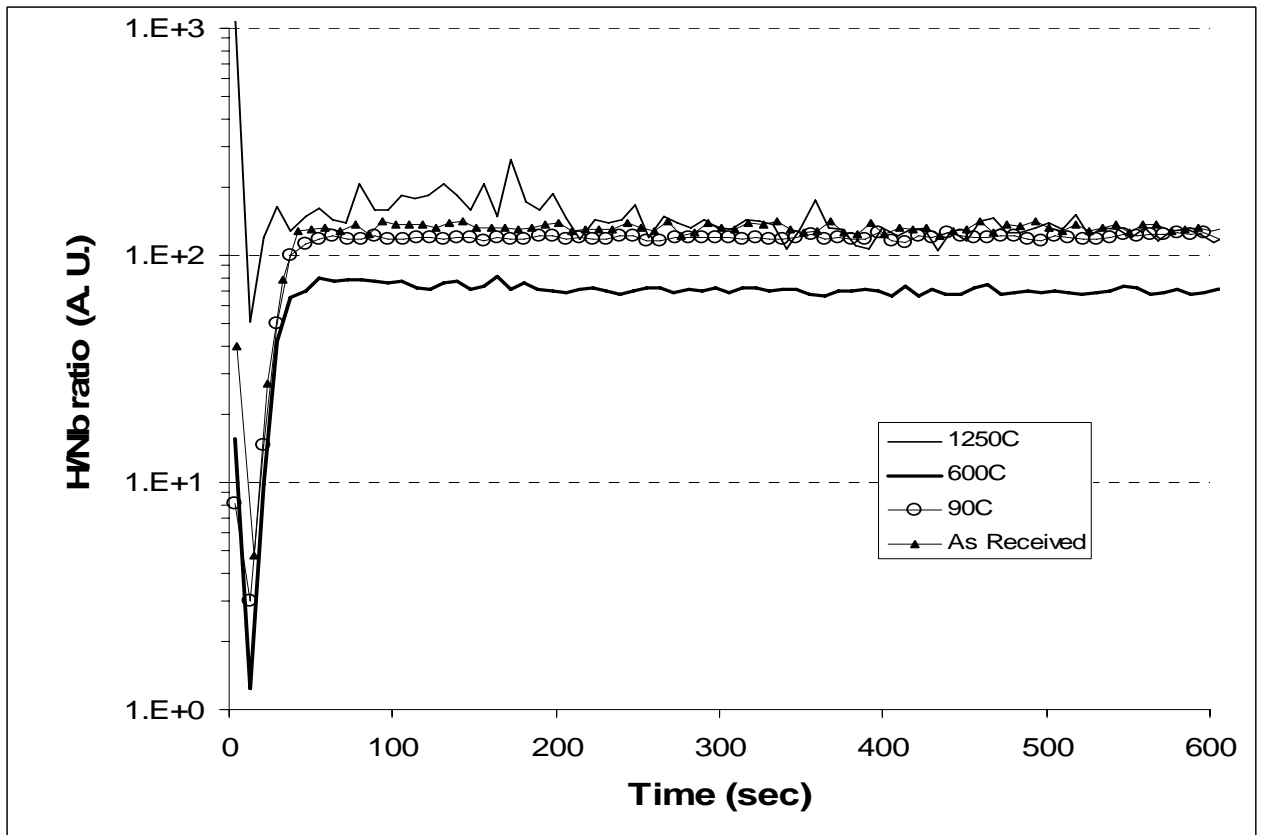

FIGURE 8. $\mathrm{H}^{-} / \mathrm{Nb}^{-}$ratio from SIMS analysis of (100) sample before and after heat treatments

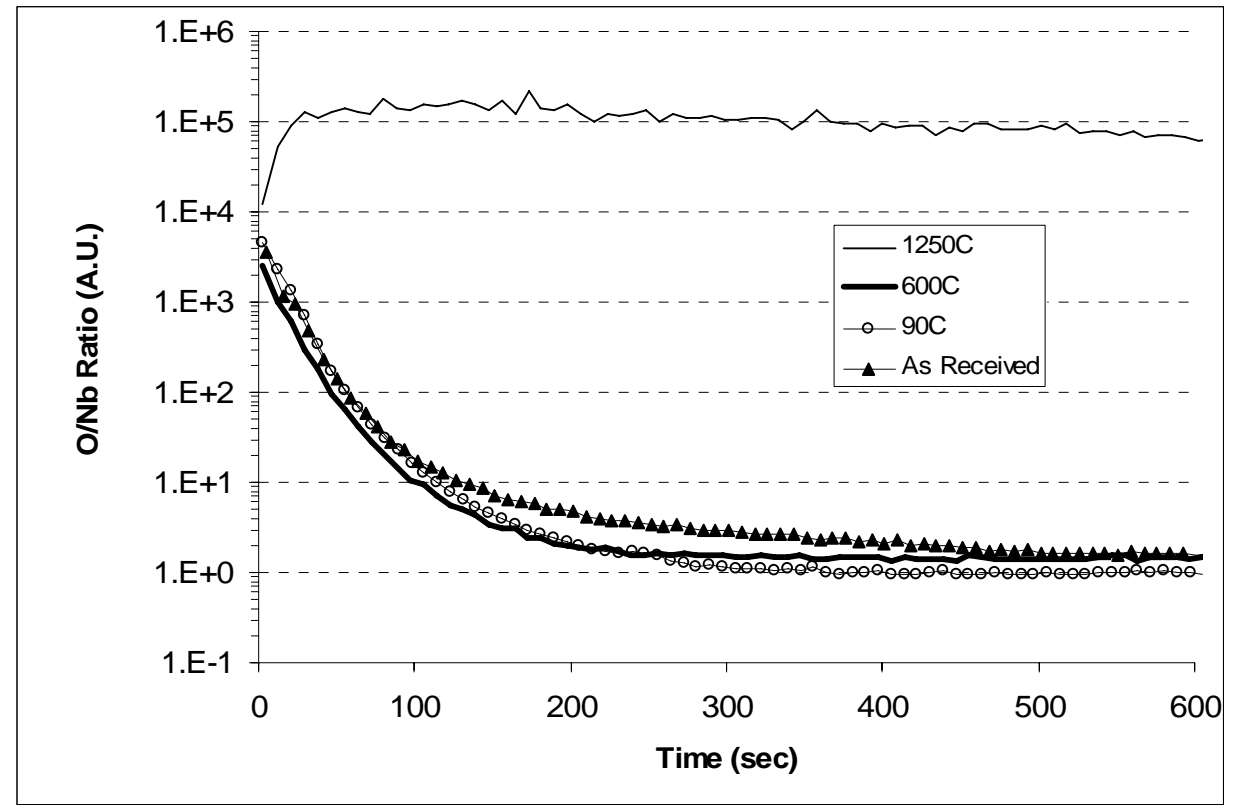

FIGURE 9. $\mathrm{O}^{-} / \mathrm{Nb}^{-}$ratio from SIMS analysis of (100) sample before and after heat treatments 


\section{0 um}

\section{कर}

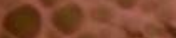

FIGURE 10. Optical image of surface of $(100) \mathrm{Nb}$ after $600^{\circ} \mathrm{C}$ heat treatment in vacuum

\section{REFERENCES}

1. J. Halbritter, Proceedings of $10^{\text {th }}$ Workshop on RF Superconductivity, Tsukuba, Japan (2001) p.292

2. R. Ballantini, et al., Proceedings of $9^{\text {th }}$ Workshop on RF Superconductivity, Santa Fe, NM (1999) p. 211

3. M. Grundner and J. Halbritter, J. Appl. Phys. 51 (1980) 397

4. H. Tian, C. E. Reece, M. J. Kelley, S. Wang, L. Plucinski, K. E. Smith, and M. M. Nowell, Appl. Surf. Sci. 253, 1236 (2006)

5. A. T. Wu, Physica C 441, 79 (2006)

6. Secondary Ion Mass Spectrometry, R. G. Wilson, F. A. Stevie, C. W. Magee, Wiley, New York (1989)

7. http://www.mateck.de/index.asp

8. Introduction to Focused Ion Beams: Instrumentation, Theory, Techniques and Practice, L. A. Giannuzzi and F. A. Stevie, Editors, Springer (2005)

9. High Resolution Focused Ion Beams: FIB and its Applications,

J. Orloff, M. Utlaut and L. W. Swanson, Kluwer Academic/Plenum Publishers (2002)

10. P. Williams, C. A. Evans, Jr., M. L. Grossbeck, H. K. Birnbaum, Anal. Chem. 48, 964 (1976) 